\title{
REGIONS IN Q1 2016: ADAPTATION TO THE NEW REALITY ${ }^{1}$
}

\author{
N.Zubarevich
}

Q1 2016 as H2 2015 demonstrated that the crisis in the regions has turned into a slow rolling phase. Everybody is gradually adapting to the new reality: industry, labor markets, and the population, which is cutting consumption in line with falling income. Regional picture has become even more eroded: the recovery growth with its drivers is nowhere in sight and the regions affected by the crisis to a greater degree have already passed the slump stage and are gradually adapting to inferior quality of life.

2016 saw the continuation of the H2 2015 trend: slowdown of the recession and stagnation at the lower level across all major indicators. In Q1 2016, industry was hardly falling $(-0.6 \%)$ due to slow growth in extracting sectors. However, recession continued in manufacturing industries (-3.1\%). Industrial production in Q1 2016 contracted in 34 regions (during 2016 - in 36).

The Vladimir, Ulyanovsk and Kurgan regions specializing in machine building as well as the Amur region have registered the deepest decline (Fig. 1). Povolzhye, Center and the North-West account for the majority of regions with deep industrial recession. Dynamics in underdeveloped republics and in the Crimea is not indicative due to low volumes of industrial production.

In Q1 2016, recession in manufacturing industry was observed in 42 regions (in 2015 - in 43 regions). Therewith, solely 25 of them posted recession in 2015. Among the industrial regions the most protracted and deep recession was posted in Kaluga, Ivanovo, Ryazan, Arkhangelsk, Samara, Orenburg, and Chelyabinsk regions, Krasnoyarsk Krai, Komi Republic, Khakasia, and Yakutiya. In Moscow, manufacturing industry has been declining for the third year in a row.

Regions with industrial production growth can be divided into two groups: with more stable positive dynamic (2015 and Q1 2016) and with recovery growth following the 2015 recession. The first group, which is rather small, comprise regions of the Center and the South with specialization in the military-industrial complex and food industry (Briansk, Voronezh, Yaroslavl, Belgorod, and Rostov regions, Stavropol Krai), several fuel and energy regions and metallurgy (Yamal-Nenets Autonomous Okrug, Sakhalin, Irkutsk, and Kemerovo regions), as well as a number of other regions. Regions with recovery growth is too early to assess on the data released for Q1. Short-term dynamic is unstable.

There is no data on investment dynamic released for Q1. However, a turning point in the three-year negative trend in 2016 is highly unlikely. This is supported by the dynamic in the construction industry, which has remained negative amid slowdown of the recession rates due to the base effect $(-1.6 \%$ for Q1 2016) which continued in 55 regions. The same number of regions posting recession was registered in 2015. 2016 demonstrates a sharp deteri-

1 This paper was originally published in Online Monitoring of Russia's Economic Outlook No.8(26). 


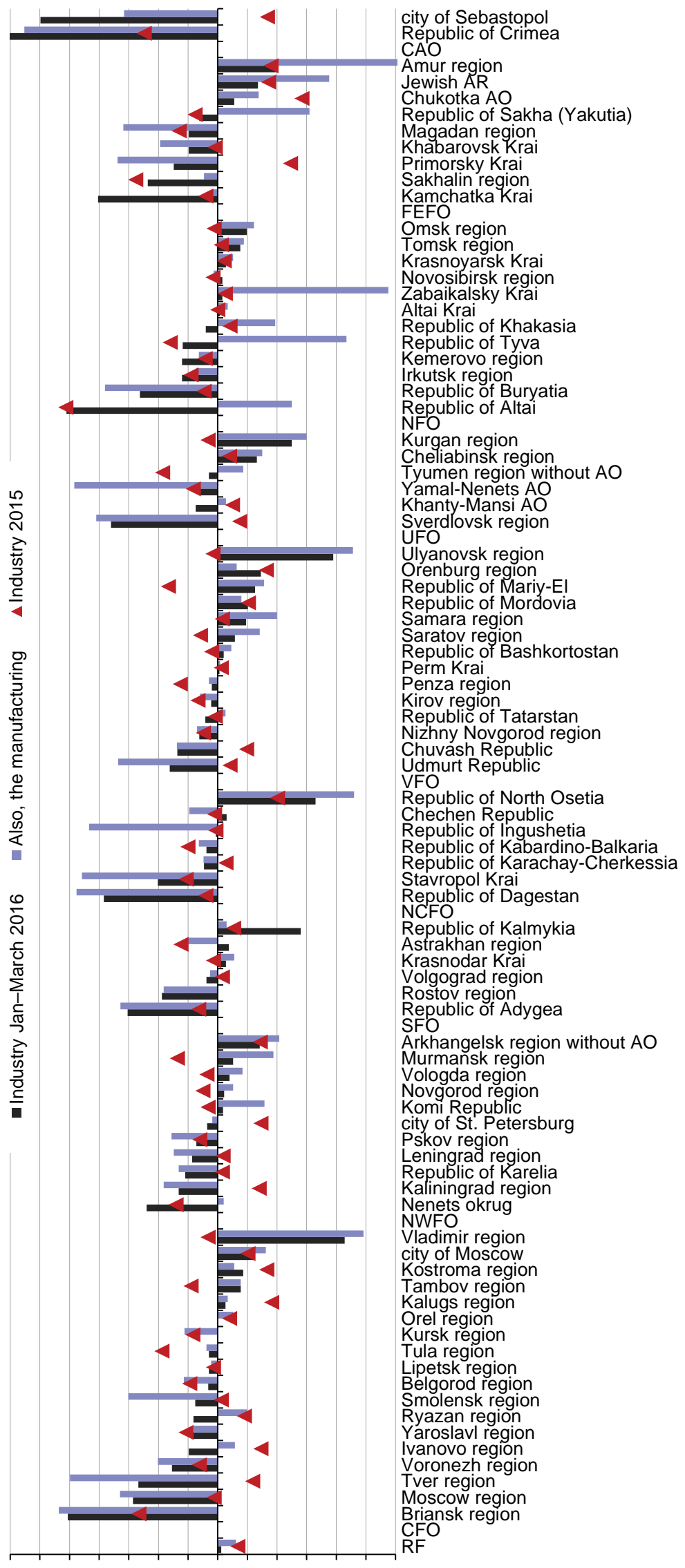

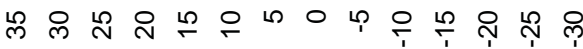


oration in the dynamics of housing construction (decline by 16\%). Reduction of commissioning of housing has taken place in 62 regions. The negative trend in this sphere was late to take shape and started only since summer 2015. That is why, the recession will be gaining momentum and will be creating problems for large cities, which amass housing construction. Most drastically the level of the housing construction fell in regions of the Urals Federal Okrug - by $43-70 \%$ excluding Khanty-Mansi Autonomous Okrug. Among the regions with high level of housing commissioning, the following regions posted the highest levels of the housing construction decrease: Tyumen, Volgograd, Chelyabinsk, Tula, Kaluga, Samara, and Novosibirsk regions and Perm Krai - by 39-55\%. The largest housing markets: Moscow, Moscow region, and St. Petersburg post significantly lower reduction rates (by 10-14\%).

Recession has slowed down in the services sector but was not halted. The volume of retail commerce fell during Q1 by $5.4 \%$. In Q2, the recession rates will be even lower compared to 2015 (69 and 79, respectively). Slow growth in the retail commerce has commenced in the Moscow and the Nizhny Novgorod regions (2-3\%); the recession is petering out in St. Petersburg (-1\%). In Moscow, the recession remained deep (11\%). Statistical data demonstrate that growth continued in Chukotka, Primorsky Krai as well as in Chechnya, Ingushetia, and Dagestan in 2015 and in 2016. However, the reliability of these data is low.

If in 2015 when the consumption slump (retail commerce) was deeper than the decline of the population's income, Russians tightened their belts at the outstripping rates. At the beginning of 2016, dynamics of two indicators nearly matched. The decline of the population's real income during January-February was estimated at $5.5 \%$. Reliability of the regional data on the population's income, especially over two months, is low, which is apparently demonstrated by the variation of dynamics indicators (Fig. 2). Nevertheless, one should note a reduction of the number of regions with ongoing recession: from 78 in 2015 to 65 in January-February 2016. The majority of regions with the population's income growth are in the Central Federal Okrug. Income of Muscovites and inhabitants of the Moscow region has also grown (by $2 \%$ and $7 \%$, respectively). The deepest and practically universal decline remained in regions of the Urals, Siberia, and the Far East. This can be explained by an increased share of variable wages (rewards, bonuses, and premiums) in extracting industries and in export sectors of primary processing, which always shrinks during crisis.

The situation of the regional labor markets remains relatively good. Arrears in wage are relatively low in volume ( $\mathrm{Rb} 4.5$ bn as of 1 April 2016) and it grew slowly (at the turn of 2015 - Rb 2bn, in December - Rb 3.9bn). By comparison, at the peak of the 2009 crisis, arrears in wages hit $\mathrm{Rb} 8.7 \mathrm{bn}$. If we divide the volume of arrears in wages as of 1 April 2016 by the headcount of large and medium enterprises and organizations, then it amounted to Rb 130 per one worker.

The highest level of arrears in wages was registered in regions of the Far East and North-West, including Primorsky Krai and the Magadan region (Rb 900-1,050 per worker), St. Petersburg and Ingushetia (around Rb 700), as well as the Murmansk region and the Kamchatka Krai (Rb 500-600). The major share is accounted for manufacturing industry and construction. Arrears in wages are the lowest in 26 regions and 8 regions boasted of their absence. Thus, this problem is not a large-scale one. 


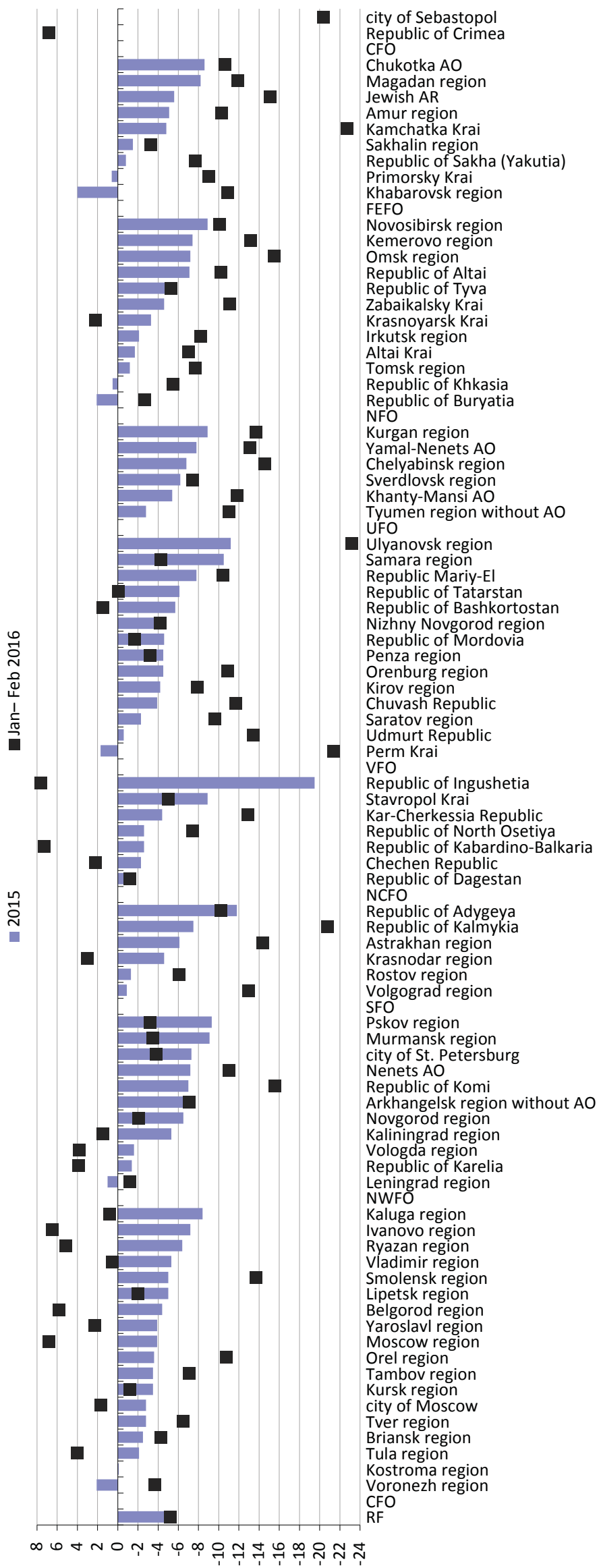




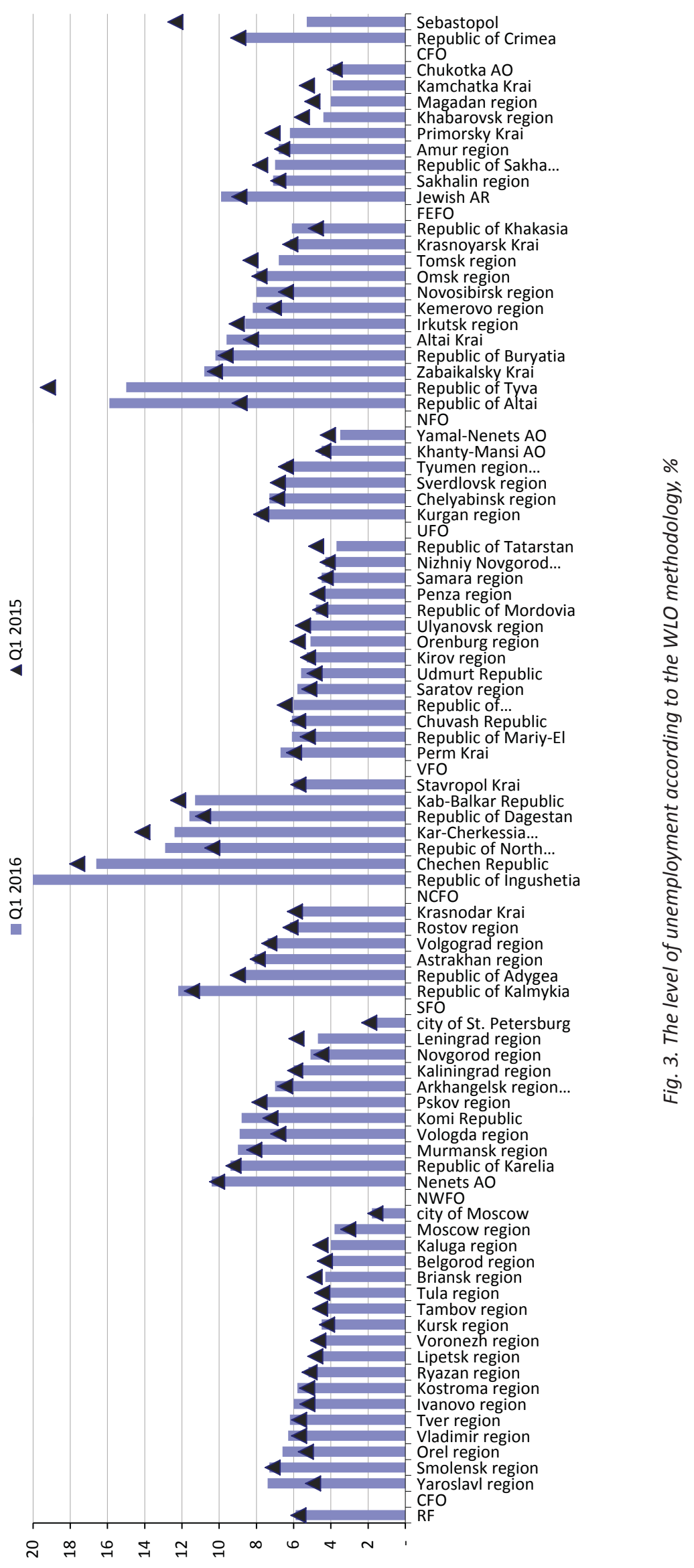


Russian business has been cutting their costs differently: with the help of part-time employment. There is not data for Q1 2016 yet, but statistics for 2015 demonstrated that the crisis on the regional labor markets is developing along the model of slow growth of part-time employment. Differentiation is due to the specialization of the regional economy. According to the data released for Q4 2015, the increased share of part-time workers, and those in downtime or administrative leave was accounted for regions with significant share of railway coach manufacturing, automobile industry, and textile industry (Samara, Kaluga, Tver, Ivanovo, and Ulyanovsk regions, Republic of Tatarstan $-5-8 \%$ of staff listing). Their part-time employment was significant throughout last year and it is highly unlikely that the data for Q1 2016 will be notably better.

So far, the crisis is not accompanied by the unemployment growth and this trend most likely with remain. The level of unemployment according to the WLO methodology in Q1 2016 is scarcely different from the indices for the same period of 2015. At the same time, one third of the regions it has somewhat decreased (Fig. 3). Volatility of indicators of underdeveloped territories is mainly due to low quality of statistics. Geographical differences of unemployment indices are also stable and are not linked with the crisis dynamics. 